\title{
LA EVALUACIÓN FORMATIVA Y COMPARTIDA COMO ESTRATEGIA PARA MEJORAR LA EFICACIA DE LOS TRABAJOS EN GRUPO: UNA EXPERIENCIA EN EDUCACIÓN FÍSICA
}

The formative and shared assessment as a strategy to improve the effectiveness of group works: an experience in Physical Education

A avaliação formativa e compartilhada como uma estratégia para melhorar a eficácia do trabalho de grupo: uma experiência em Educação Física

\section{Raúl Martínez Benito}

Colegio Montessori Salamanca. Correo electrónico: raulinef05@hotmail.com

\section{Resumen}

En esta experiencia se presenta la relación entre los procesos de evaluación formativa y compartida y el estilo actitudinal aplicados en una unidad didáctica de combas en Educación Física. En ella, a través de un proyecto de trabajo cooperativo, los alumnos han creado como producto final una coreografía. Intentaremos explicar cómo estos procesos han permitido al profesor tener un conocimiento mayor sobre el proceso de trabajo de los grupos, a intervenir para evitar o modificar aquellas conductas y situaciones negativas para el grupo, y así mismo, para reforzar y animar a que se repitieran aquellas actitudes que sí incidían positivamente en el mismo.

Palabras clave: Evaluación formativa; aprendizaje cooperativo; estilo actitudinal

\section{Abstract}

With this experience we want to share the processes of formative and shared evaluation applied in a didactic unit of skip ropes in Physical Education subject. In this unit, through a project of cooperative work, the students have created as final product a choreography. We will try to explain how these processes have allowed the teacher to have a better knowledge about the work process of the groups, to interced, avoid or modify those behaviors and negative situations for the group, and also, to reinforce and encourage to repeat those attitudes with a positive effect on it.

Keywords: Formative assessment; cooperative learning; attitudinal style

La evaluación formativa y compartida como estrategia para mejorar la eficacia de los trabajos en grupo: una experiencia en Educación Física 


\section{Resumo}

Nesta experiência, a relação entre os processos de avaliação formativa e compartilhada e estilo comportamental aplicada de uma unidade didáctica Combas apresentado em Educação Física. Nele, através de um trabalho de projecto cooperativa, os alunos criaram uma coreografia como um produto final. Tente explicar como esses processos têm permitido o professor a ter uma melhor compreensão dos grupos de processos de trabalho, a intervir para impedir ou modificar esses comportamentos e situações negativas para o grupo e, também, para fortalecer e incentivar você repetir os sim, eles imiscuiu atitudes positivamente nele.

Palavras-chave: Avaliação formativa; aprendizagem cooperativo; estilo do comportamento

\section{Introducción}

La educación actual se inclina, cada vez más, por el uso de metodologías activas cuya aplicación plantea nuevos problemas de procedimiento a los docentes. En el caso de la Educación Física, nuestro interés se centra en aquellas que plantean situaciones de aprendizaje en grupo, donde las actitudes y las acciones de cada integrante son determinantes para el éxito de la tarea. Coincidimos con Velázquez (2013) en que la falta de experiencia del alumnado para trabajar eficazmente en grupo suele ser un condicionante, y que es preciso enseñar a trabajar en grupo con eficacia si queremos obtener resultados positivos en las propuestas didácticas posteriores.

Somos los profesores quienes debemos reflexionar y encontrar la manera de orientar a nuestros alumnos a compartir su trabajo y aprendizaje con otros. En este sentido, creemos que los procesos de evaluación formativa y compartida (López-Pastor, 2006) ayudan a mejorar la eficacia en este proceso. Las habilidades sociales necesarias para trabajar en equipo se pueden ver reforzadas a través de procesos de evaluación, en los cuales se incluyan aspectos relacionados con la escucha activa, la distribución del tiempo, las ayudas entre compañeros y la contribución individual al trabajo grupal (León de Barco, 2002; Velázquez, 2010). Ese es el objeto de la siguiente experiencia de evaluación, tener un conocimiento mayor sobre el proceso de trabajo de los grupos para intervenir sobre ellos y mejorar su eficacia.

La evaluación formativa y compartida como estrategia para mejorar la eficacia de los trabajos en grupo: 


\section{Contextualización}

La experiencia se ha llevado a cabo en el colegio concertado Montessori de Salamanca. Se ha aplicado en la unidad didáctica (UD a partir de ahora) de combas con los dos grupos de $1^{\circ} \mathrm{ESO}$, formados por 27 (15 niños y 12 niñas), y 26 (10 niñas y 16 niños) alumnos respectivamente.

\section{Diseño y desarrollo}

Respecto a la metodología para el desarrollo de la UD hemos aplicado el Estilo Actitudinal (Pérez-Pueyo, 2005), incluyendo la enseñanza recíproca como técnica de Aprendizaje cooperativo (Velázquez, 2013). La UD se divide en dos fases: una primera donde los alumnos aprenden a saltar en diferentes elementos de comba, para en la segunda, en grupos, utilizar lo aprendido para realizar un montaje final (Pérez-Pueyo y Vega Cobo, 2006).

Respecto a la evaluación formativa, la entendemos como una "actividad crítica de aprendizaje” (Álvarez-Méndez, 2001, p.12) con la que pretendemos que nuestros alumnos adquieran conocimiento, es decir, con ella buscamos que el alumno corrija sus errores para aprender más y mejor (López-Pastor, 2006). A continuación exponemos los tres procesos de evaluación formativa llevados a cabo, con sus correspondientes instrumentos utilizados:

a) Al finalizar cada día de trabajo, el grupo rellena la ficha de autoevaluación (Figura 1), con el objetivo de reflexionar sobre los siguientes aspectos:

- Cumplimiento de los plazos de trabajo establecidos, y en el caso de no haberlo hecho buscar el motivo, con el fin de no repetir mismos errores en los siguientes días.

- Conflictos surgidos en el grupo y posibles maneras de resolverlos.

- Actitud y cumplimiento de las normas de clase por cada uno de los integrantes del grupo.

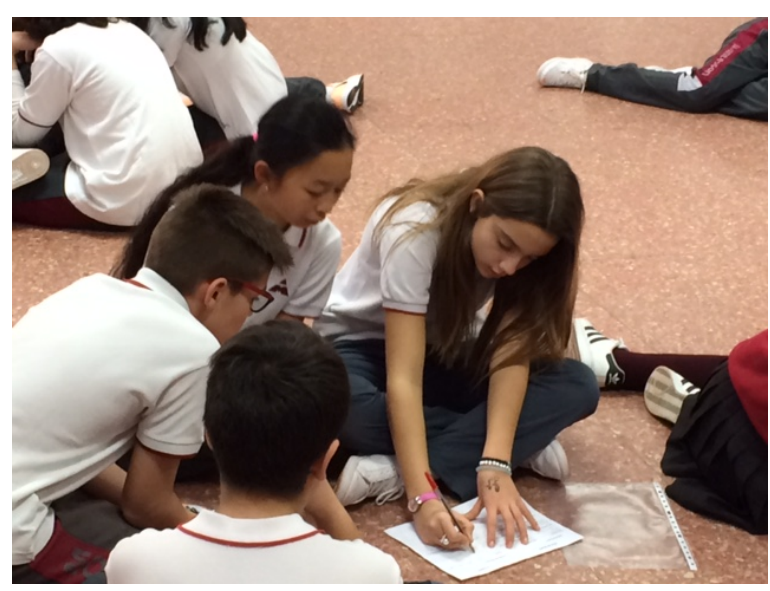

Figura 1. Grupo autoevaluándose

La evaluación formativa y compartida como estrategia para mejorar la eficacia de los trabajos en grupo: una experiencia en Educación Física 
b) Siguiendo las sugerencias del profesor Velázquez en conversación personal con el autor de este trabajo, llevamos a cabo el siguiente proceso: Antes de comenzar la sesión, el grupo lee los comentarios que el profesor ha escrito para ellos, sobre el trabajo realizado el día anterior. Además de complementar la información recogida en la ficha de autoevaluación grupal, esta actividad busca que todos los grupos conozcan la visión del profesor sobre cómo están desarrollando su trabajo. El profesor, a través de lo observado y anotado durante la clase, anima al grupo, refuerza las conductas positivas detectadas, y/o aconseja maneras de proceder sobre aspectos relacionados con las habilidades sociales u organización del grupo.

c) Al inicio de la fase 2, el profesor explica las condiciones que ha de cumplir la coreografía. Entrega y explica los criterios de calificación recogidos en una rúbrica (Tabla 1). Días antes de la exposición final, cada grupo expone su trabajo en dos ocasiones, y se les evalúa sobre el grado de consecución de los criterios. El resto de los grupos también aconsejan a sus compañeros, aportándoles ideas o soluciones a los problemas o errores cometidos. Esta información la utiliza el grupo en sesiones posteriores para ir corrigiendo y puliendo la coreografía (Pérez-Pueyo, 2005).

Tabla 1.

Resumen procesos de evaluación formativa fase 2 de la UD.

\begin{tabular}{|c|c|c|c|}
\hline & ¿Cuándo se realiza? & Instrumento eval. & ¿Quién evalúa? \\
\hline $\begin{array}{c}\text { Autoevaluación } \\
\text { Grupal }\end{array}$ & $\begin{array}{c}\text { Diariamente } \\
\text { (final de la sesión) }\end{array}$ & $\begin{array}{c}\text { Registro anecdótico } \\
\text { estructurado } \\
+ \\
\text { Lista de control }\end{array}$ & $\begin{array}{c}\text { Grupo } \\
\text { (Autoevaluación) }\end{array}$ \\
\hline $\begin{array}{c}\text { Lectura } \\
\text { observaciones }\end{array}$ & $\begin{array}{c}\text { Diariamente } \\
\text { (inicio de la sesión) }\end{array}$ & Registro anecdótico & $\begin{array}{c}\text { Profesor } \\
\text { (Heteroevaluación) }\end{array}$ \\
\hline $\begin{array}{l}\text { Exposición } \\
\text { coreografía }\end{array}$ & $\begin{array}{l}\text { Antes de finalizar la } \\
\text { fase de montaje }\end{array}$ & Rúbrica & $\begin{array}{c}\text { Profesor } \\
\text { (Heteroevaluación) + } \\
\text { Compañeros (Co- } \\
\text { evaluación) }\end{array}$ \\
\hline
\end{tabular}

\section{Conclusiones}

La aplicación de los diferentes procesos de evaluación formativa nos ha permitido tener una mayor información de lo que iba ocurriendo en los grupos. La necesidad de tener que observarlos trabajando, para después proporcionarles información por escrito, nos obliga a centrar conscientemente la atención en aspectos concretos: cómo se toman las 
decisiones, qué conflictos surgen, cómo pueden ser solucionados y organizarse como grupo.

$\mathrm{Al}$ principio de cada clase los alumnos se mostraban muy interesados en leer los comentarios que había escrito el profesor para ellos. Resultó ser una forma muy cómoda de captar su atención y concentración inicial hacia el trabajo. Era una ocasión ideal para reforzar aquellas conductas que afectaban positivamente al grupo.

En cuanto a la posibilidad de exponer previamente la coreografía les sirvió, en primer lugar, para entender (si no lo habían hecho ya), el significado de cada uno de los criterios recogidos en la rúbrica. Este proceso les permitió en las sesiones posteriores centrar su atención en aquellos criterios que no cumplían a la perfección y podían mejorar. Además, el proceso contribuyó a crear un clima positivo en clase, por la posibilidad de ayudarse unos grupos a otros dándose consejos.

\section{Referencias}

Álvarez-Méndez, J. M. (2001). Evaluar para conocer, examinar para excluir. Madrid: Morata.

León de Barco, B. (2002). Elementos mediadores en la eficacia del aprendizaje cooperativo: entrenamiento en habilidades sociales y dinámicas de grupo. Tesis doctoral. Cáceres: Universidad de Cáceres, España.

López-Pastor, V. M. (Coord.) (2006). La Evaluación en Educación Física. Revisión de los modelos tradicionales y planteamiento de una alternativa: la evaluación formativa y compartida. Buenos Aires: Miño y Dávila.

Pérez-Pueyo, A. (2005). Estudio del planteamiento actitudinal del área de Educación Física de la Educación Secundaria Obligatoria en la LOGSE: Una propuesta didáctica centrada en una metodología basada en actitudes. Tesis doctoral. León: Universidad de León, España.

Pérez-Pueyo, Á., \& Vega, D. (2006). El trabajo de combas desde una metodología basada en actitudes. Aplicación del estilo actitudinal a la etapa primaria. In C. Velázquez (Ed.), Actas del V Congreso Internacional de Actividades Físicas Cooperativas [CD-Rom] (pp. 1-16). Laguna de Duero (Valladolid): La Peonza Publicaciones.

La evaluación formativa y compartida como estrategia para mejorar la eficacia de los trabajos en grupo: 
Velázquez, C. (2013). Análisis de la implementación del aprendizaje cooperativo durante la educación obligatoria en el área de Educación Física. Tesis Doctoral. Valladolid: Universidad de Valladolid, España.

Velázquez, C. (2010). Aprendizaje cooperativo en Educación Física. Barcelona: Inde. 